\title{
Hypothetical Physics and Chemistry of Volcanic Eruptions: The Doorway to Their Prediction
}

\author{
Arie Lev Gilat ${ }^{1}$, Strachimir Cht Mavrodiev ${ }^{2}$, Alexander Vol ${ }^{3}$ \\ ${ }^{1}$ Geological Survey of Israel (Ret.), Jerusalem, Israel \\ ${ }^{2}$ INRNE-BAS, Sofia, Bulgaria \\ ${ }^{3}$ OSHADI Drug Administration Ltd., Rehovot, Israel \\ Email: levgilat@gmail.com
}

How to cite this paper: Gilat, A.L., Mavrodiev, S.C. and Vol, A. (2019) Hypothetical Physics and Chemistry of Volcanic Eruptions: The Doorway to Their Prediction. International Journal of Geosciences, 10, 377-404.

https://doi.org/10.4236/ijg.2019.104022

Received: February 10, 2019

Accepted: April 19, 2019

Published: April 22, 2019

Copyright $\odot 2019$ by author(s) and Scientific Research Publishing Inc. This work is licensed under the Creative Commons Attribution International License (CC BY 4.0).

http://creativecommons.org/licenses/by/4.0/

\begin{abstract}
This article presents a further development of the hypotheses concerning the possibility of predicting ("tectonic") earthquakes [1]. Those hypotheses are based on the conversion of all types of released energy into heat and active chemical substances. One of the important sources of this phenomenon is the release of the latent energy trapped and stored during the Earth's accretion. The latent energy of primordial hydrogen and helium escaping from the Earth's core and lower mantle causes degassing processes [2] [3]. This latent energy converts into totally different types of chemical, electromagnetic and thermal energies of active compounds that are responsible for the major endogenic terrestrial processes. The dominating theories in seismology and volcanology are that an earthquake results from a sudden slip of a tectonic fault and that only magma and the gases contained in magma supply the volcanic energy resulting in the conclusions that earthquakes and eruptions are unpredictable. Volcanic eruption is considered herein to be a special case of the earthquake-process in which earthquake hypocenters rise to the Earth's surface. A possible solution is proposed ([1] and herein) based on the analyses of the physicochemical processes as participants in earthquake and eruption preparations (foreshocks - major shock - aftershocks - volcanic eruptions) and on the characteristic rates of reflection of these processes on the Earth's surface. Influences of Sun-Moon-tides and volcanic ("harmonic") tremors are analyzed from physical-chemical point of view. The case of the 1980 eruption of Mount St. Helens and the proposed monitoring of the recommended additional data provides a way of selecting a complex of reliable earthquake and volcanic eruption precursors.
\end{abstract}

\section{Keywords}

Earthquakes, Volcanic Eruptions, Energy Sources, Physical Chemistry, 
Precursors, Electromagnetic Field Monitoring

\section{Introduction}

Earthquakes and volcanic eruptions are described in most studies separately and explained differently. However, they are related in space (Figure 1) and time. Earthquakes precede and accompany volcanic eruptions, but not every earthquake culminates in a surface eruption. Most of them situate in deep-seated faults at plate boundaries, rifts, and transform faults. The classical Reid's [4] model of the "earthquake as a result of rock displacement under accumulated elastic stress" cannot help with earthquake prediction [5] and cannot explain the observed earthquake-cycle, foreshocks - main shock - aftershocks of the strong earthquake, as well as from where comes the monstrous energy of great earthquakes and volcanic eruptions [2] [3]. There are clear demonstrations that the reasons for most of the "tectonic earthquakes" are natural underground explosions, which often cause in their epicenters, the acceleration in the vertical direction that exceeds the acceleration of gravity ([6] and Table 1).

The elastic energy of "semi-solid mantle and lithosphere" breaks cannot cause such motion or the energy release in principle [7]. The energy release and the dominant vertical component of Earth's surface motions [8] [9] [10] support the claim that explosion is a basic mechanism of earthquake. The clue to its energy source is the anomalous flow of the Earth's core lower mantle hydrogen and helium (Figure 2, Figure 3), enriched by its light isotope ${ }^{3} \mathrm{He}$ [2] [3] [11]. This flow accompanies earthquakes and volcanic eruptions as well as provides the evidence that volcanic eruption is a variety of "tectonic earthquake" wherein its hypocenter rises to the earth-surface [2] [3]. The additional evidence, the ability of earthquake to generate heat, is effectively demonstrated by the 1994 Bolivian earthquake $(M \mathrm{w}=8.3$, focal depth $=635 \mathrm{~km})$, which should be more appropriately viewed as a thermal process rather than a mechanical process. That earthquake observed as seismic waves, was only a small part of the whole process. Its thermal energy of $1.35 \times 10^{18} \mathrm{~J}$ was comparable to the total thermal energy released during large volcanic eruptions such as the 1980 Mount St Helens eruption [12].

Many additional cases of monstrous generations of heat before a major shock were described recently [e.g. [13], figure 2, references there]. Furthermore, large earthquakes sometime trigger other large earthquakes thousands of kilometers away, or induce thermal anomalies at active volcanoes at a distance of thousands of kilometers away with a delay of only 1 to 21 days [14]. Charles Darwin observed a similar phenomenon on February 20, 1835 in Valdivia, Chile, where the great earthquake activated several Chilean volcanoes and came to the conclusion that great earthquakes and volcanic eruptions have unknown chemical reactions as their common energy source [15]. 


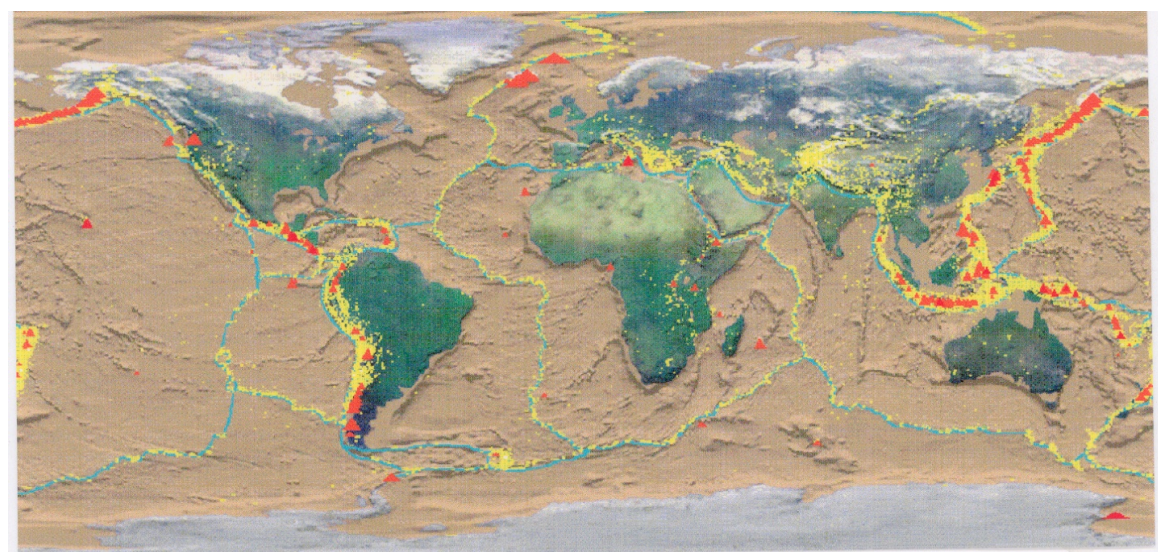

Figure 1. Computer-generated surface map of the planet Earth showing plate margins (blue lines), illustrating a good correlation of active volcanoes (red triangles) with earthquake epicenters (yellow dots) (Compiled after Internet data, mainly provided by USGS Smithsonian Institution sites and NOAA/NGDC).

Table 1. Ground motion database for some of the earthquakes epicenter-areas.

\begin{tabular}{cccccc}
\hline $\begin{array}{c}\text { Kathmandu, Nepal } \\
\text { November 29-30, 2009 }\end{array}$ & \multicolumn{5}{c}{$\begin{array}{c}\text { International Seminar on } \\
\text { Hazard Management for Sustainable Development }\end{array}$} \\
\hline Event & Station (Mw) & Hor-1 (g) & Hor-2 (g) & Ver (g) & V/H \\
\hline Gazli, Uzbekistan 1976 & Karakyr (6.8) & 0.71 & 0.63 & 1.34 & 1.89 \\
Imperial Valley, USA 1979 & El Centro Array 6 (6.5) & 0.41 & 0.44 & 1.66 & 3.77 \\
Nahanni, Canada 1985 & Site 1 (6.8) & 0.98 & 1.1 & 2.09 & 1.9 \\
Morgan Hill, USA 1989 & Gilroy Array\#7 (6.2) & 0.11 & 0.19 & 0.43 & 2.25 \\
Loma Prieta, USA 1989 & LGPC (6.9) & 0.56 & 0.61 & 0.89 & 1.47 \\
Northbridge, USA 1994 & Arleta Fire Station (6.7) & 0.34 & 0.31 & 0.55 & 1.61 \\
Kobe, Japan 1995 & Port Island (6.9) & 0.31 & 0.28 & 0.56 & 1.79 \\
Chi Chi, Taiwan 1999 & TCU 076 (6.3) & 0.11 & 0.12 & 0.26 & 2.07 \\
\hline
\end{tabular}

In this article, tectonic earthquake and eruption processes are discussed as a series of chemical explosions caused by physicochemical processes, partly reflected on Earth's surface in which a volcanic eruption is argued as a special case of earthquake where the hypocenter rises to the Earth's surface, forming a volcanic chamber at a shallow depth [2] [3]. Explosives (reactive gases) are produced by the flow of primordial $\mathrm{H}$ and $\mathrm{He}$ from the core and the lower mantle, where the pressure-temperature (PT) can exceed 1,000,000 atm. and $5000 \mathrm{~K}$, into the atmosphere and furthermore into the plasmosphere (Figure 2, Figure 3, Table 2). This flow is undeniably a major energy source and can be easily transferred from mantle plume along major faults, quickly concentrated, focused and explosively released, thus producing very high velocities of energy release and all the geophysical and geochemical anomalies typical of earthquakes.

Concentrations of highly explosive clusters are responsible for the observed intermediate "quakes" (foreshocks - major shock - aftershocks) within their 


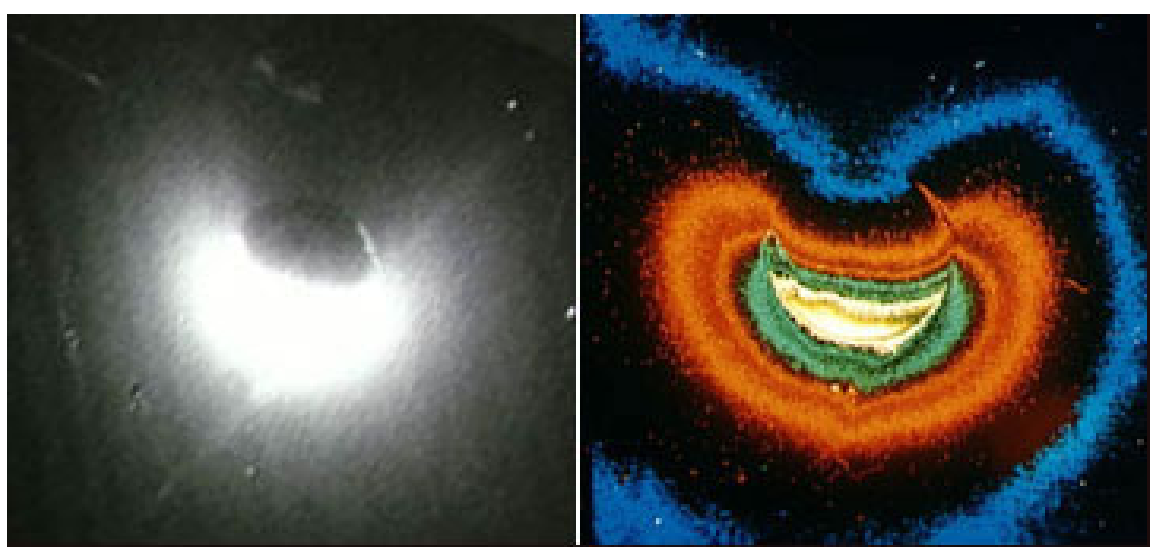

Figure 2. Hydrogen in the Exosphere is clearly identifiable in ultraviolet images. Figure 2 is one of the first images of the geocorona which was taken in 1972 by astronaut John Young while on the Moon. The Apollo 16 mission carried a U.S. Navy ultraviolet camera that observed the stars and also produced this striking photo (far left) of hydrogen in the plasmasphere around the Earth. It was colorized (left) to show brightness variations (https://science.nasa.gov/science-news/science-at-nasa/1999/ast16feb99_1/). Taken from the site

https://malagabay.wordpress.com/2013/04/11/terrestrial-degassing-of-hydrogen-and-heli $\underline{\mathrm{um} / .}$.

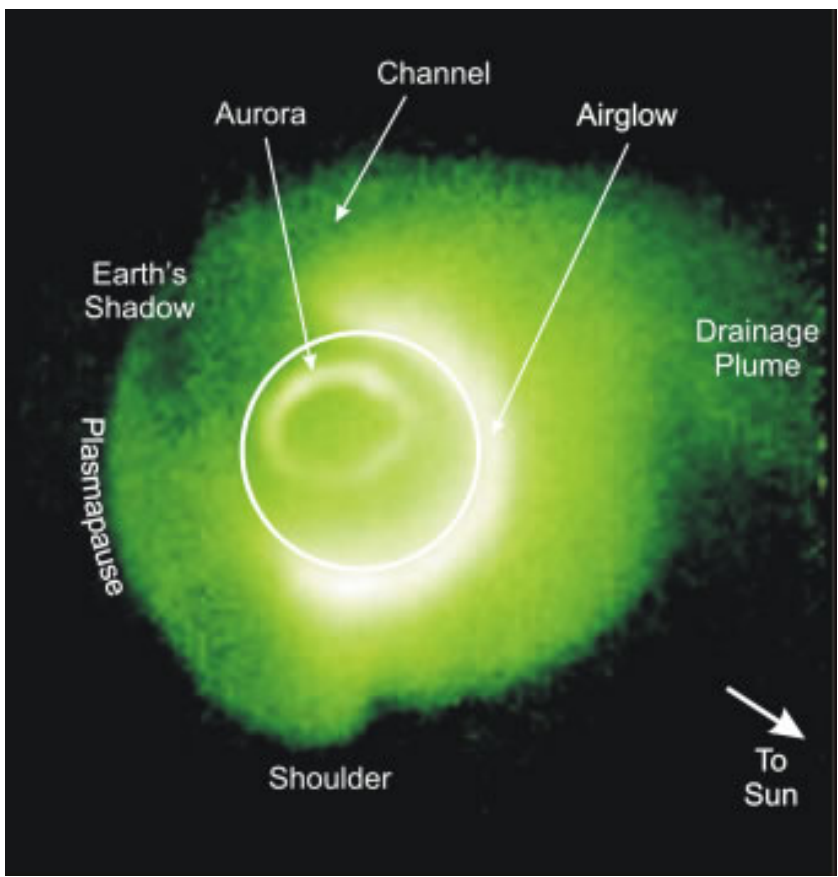

Figure 3. Helium in the Exosphere is also clearly identifiable in ultraviolet images. Earth's plasmasphere at $30.4 \mathrm{~nm}$. This image from the Extreme Ultraviolet Imager was taken at 07:34 UTC on 24 May 2000, at a range of 6.0 Earth radii from the center of Earth and a magnetic latitude of 73 N. (From Sandel, B. R., et al., Space Sci. Rev., 109, 25, 2003.) http://euv.lpl.arizona.edu/euv/. Taken from the site https://malagabay.wordpress.com/2013/04/11/terrestrial-degassi ng-of-hydrogen-and-helium/. 
Table 2. Specific latent energy of helium and hydrogen (taken from [2]).

\begin{tabular}{ccccc}
\hline Depth & Pressure & Temperature & \multicolumn{2}{c}{ Specific energy $(\mathrm{J} / \mathrm{mol})$} \\
\hline$(\mathrm{km})$ & $(\mathrm{Gpa})$ & $(\mathrm{K})$ & Helium & Hydrogen \\
\hline 0 & 0 & 300 & 12,480 & 8652 \\
10 & 0.3 & 500 & 20,800 & 14,420 \\
100 & 3.4 & 1800 & 74,880 & 51,912 \\
500 & 18 & 2000 & 83,200 & 57,680 \\
1000 & 40 & 2500 & 104,000 & 72,100 \\
2000 & 88 & 3500 & 145,600 & 100,940 \\
3000 & 160 & 5500 & 228,800 & 158,620 \\
4000 & 238 & 5800 & 241,280 & 167,272 \\
5000 & 321 & 6000 & 249,600 & 173,040 \\
6000 & 358 & 6200 & 257,920 & 178,808 \\
\hline
\end{tabular}

ascending hypocenters. Cold nuclear synthesis (fusion) and natural fission reactions are also under consideration as the major internal energy sources. The whole assemblage of hypocenter preparation processes is accompanied by the generation of electromagnetic fields, which in contrast to other processes, are instantly reflected on the Earth's surface.

The conclusions of many of the last years' studies are that geodynamics of the high-seismicity regions and the nature of great earthquakes are related more to the mantle plumes and not to movements along the particular faults [16]. Moreover, the slowing of Africa's motion between 67 and 52 million years ago and the synchronously unusually rapid motion of the Indian plate, its push to collision with Eurasia causing huge scale seismicity and eruptions of the Deccan flood basalts, were all convincingly related to the force of the Reunion plume head [17].

Mantle plumes, the hypothetical thermal diapirs that are supposed to solve the energy problems of the theory of plate tectonics, are supposed to do this by carrying heat from the liquid core upward to the lithosphere in narrow rising columns supposedly driven by convectional heat exchange and independent of plate motions. However, their formation on the liquid core to lower mantle boundary and the driving force cannot be explained by the hypothetical temperature difference between the uppermost liquid core and the lowermost mantle. The big difference between the magma's specific heat capacity ( $0.35 \mathrm{cal} / \mathrm{g}$ degree) and it's heat of fusion (120 - $165 \mathrm{cal} / \mathrm{g}$ under atmospheric pressure) for melting magma, demands an amount of energy higher than for heating it to $400^{\circ} \mathrm{C}$; thus, being $300^{\circ} \mathrm{C}-400^{\circ} \mathrm{C}$ hotter than the surrounding rock as the only energy resource at the core-mantle boundary, these plumes cannot melt-through the almost $3000 \mathrm{~km}$ thick solid mantle. Even more doubtful is the possibility that their plume head could provide (described above) additional energy supply on a planetary scale [17]. We will try to show herein that the additional mentioned 
above energy sources can solve the unresolved energy lack problem of the mantle plumes, earthquakes and volcanic eruptions (Chapter 2 and 3).

The authors call the readers' attention to the role of Sun-Moon tides as earthquake triggers ([1] and Chapter 4) as well as to the physico-chemical mechanisms of volcanic ("harmonic") tremors, which have been always noticed as a part of preparation of the volcanic eruption (Chapter 5). The cases of regional earthquakes supplying energy through mantle plumes and liquid core and in such a manner triggering other earthquakes and enhancing volcanic eruptions are discussed in Chapter 6. Chapter 7 contains the case story of the 1980 eruption of Mount St. Helens and its discussion. Monitoring of additional data provides a way of selecting a complex of reliable earthquake and volcanic eruptions precursors.

Principles and results of forecasting of the regional imminent seismic activity based on the analysis of one minute of INTERMAGNET geomagnetic field data and NASA codes for Sun-Moon tides - Geomagnetic Quake (GQ) are also described. Examples of prediction of the period, magnitude, depth, and coordinates of the hypocenter of an impending earthquake are based on the Inverse Problem Method for the analysis of monitoring data variations of geoelectromagnetic fields. The necessary and sufficient conditions for the existence of a solvable inverse problem are formulated based on the Dubna method for discovering the hidden dependences. The accuracy of prediction will depend on the values of depth, coordinates, time, magnitude of the impending earthquake, number of monitoring points, geology of the region, and on the ill-posed quality of the received over determined non-linear algebraic system [1] [18] [19] [20] [21].

\section{Degassing Energy Flows and their Effects: Mantle Plumes, Earthquakes, Volcanic Eruptions}

The authors of references [2] [3] have proposed a conceptual system of hypotheses, which explains that during Earth's accretion, primordial hydrogen and helium (enriched in ${ }^{3} \mathrm{He}$ ) were trapped and stored in the planet's interior as $\mathrm{He}$ and $\mathrm{H}$-interstitial solutions and compounds, stable only under ultrahigh PT-conditions, which were discovered in recent experiments. The endothermic reactions of their generation provided effective cooling of the planet and prevented its evaporation, where the end products of those reactions were more compact than the initial gases. Since stabilization of our planet, exothermic processes of $\mathrm{H}$ and $\mathrm{He}$ degassing became dominant, releasing the energy invested in their generation.

The specific energy of the core-lower mantle $\mathrm{H}$ and $\mathrm{He}$ was calculated with ${ }^{3} \mathrm{He}$ serving as a unique measuring transformer correlative to the internal heat flow. Multiplying its flow from the lower mantle by the highest coefficient of correlation results in $5.12^{\star} 10^{20} \mathrm{~J}$ /year, an amount of energy five-fold greater than the entire energy loss involved in all earthquake and volcanic activity ([2] [3] references there). In distinction to the five of the Earth's other main sources of 
the internal energy (cold fusion nuclear reactions, natural fission reactions, radioactive decomposition of $\mathrm{U}$, Th and ${ }^{40} \mathrm{~K}$, gravitational differentiation in the Earth's liquid core and the energy of lunar tides), the chemical energy can be carried by the reactive "volcanic" gases, and concentrated and focused in the mantle-plumes, generating great earthquakes and volcanic eruptions. This energy is: a) quasi-constantly released during billions of years of the Earth's existence and practically limitless; b) can be quickly concentrated and focused; c) is of very high density; d) offers very high velocities of energy release; e) has small losses during transportation over long distances [2] [3].

This mass transfer related energy, in contrast to energy from traditional sources, generates convection in the Earth's liquid core and produces liquid magma in the mantle and supplies energy to rising plumes. It can be easily transferred from the plumes along major faults and their branches, quickly concentrated and explosively released, thus producing very high velocities of energy release and all the geophysical and geochemical anomalies typical of earthquakes. Concentrations of highly explosive clusters are responsible for the observed intermediate "quakes" (foreshocks - major shock - aftershocks) within their ascending hypocenters. Whole assemblage of hypocenter preparation processes is accompanied by generation of electromagnetic fields, which in contrast to other processes, are instantly reflected on the Earth's surface.

In summary: $\mathrm{H}$ - and He-sublimation from the solid and convection in the liquid core with flux melting the solid mantle generates gas-liquid scavenging plumes. $\mathrm{H}$ - and He-release are accompanied by an intense release of their stored specific (latent) energy (Table 2). Their ionization and incorporation into different chemical compounds are followed by decomposition due to local and gradual PT-changes. Ongoing compressions-decompressions (foreshocks - major shock - aftershocks) within an upward moving hypocenter (up to the magma chamber), accompanied by additional releases of energy, cause release of elemental $\mathrm{H}, \mathrm{O}, \mathrm{C}, \mathrm{S}, \mathrm{Cl}, \mathrm{F}$ etc. This process induces explosive or combustive syntheses of $\mathrm{H}_{2} \mathrm{O}, \mathrm{SO}_{2}, \mathrm{H}_{2} \mathrm{SO}_{4}, \mathrm{CO}_{2}, \mathrm{H}_{2} \mathrm{~S}, \mathrm{HCL}, \mathrm{HF}$ and other compounds in accordance with local changes of $\mathrm{PT}$ and energy, in accordance with the Principle Le Chatelier-Braun "The Equilibrium Law" ("whenever a system in equilibrium is disturbed the system will adjust itself in such a way that the effect of the change will be nullified".).

The present volcanological paradigm postulates that only magma and its contents are responsible for all the energy supply of the plutonic processes. However, we know many cases of volcanic eruptions which only produce tremendous amounts of gases. The common observation is that the total amounts of chemicals released to the atmosphere by volcanic activity is usually many-fold greater than that which could be contained in the extruded amounts of lava or ash ([2] [3] references there). As an example, Fedotov [22] calculated the heat-power of the burning gas-eruption column of the northern Tolbachinsk (Kamchatka) fissure-eruption (6.7.1975 - 10.12.1976), which erupted for 72 days with about 0.68 $\mathrm{km}^{3}$ of small-size pyroclastics, which was $3.52^{\star} 10^{10} \mathrm{cal} / \mathrm{sec}=1.47^{\star} 10^{5} \mathrm{Mw}$ "; for 
comparison, "the power of all the USSR power-stations in 1976 was 228,000 $\mathrm{Mw}$ ", or $2.28^{\star} 10^{5} \mathrm{Mw}$ [22]. We think that this is a case of a separate from magma three-dimensional reactive gas transfer, and there is no correlation between volumes of magma and erupting gases.

The pathways of magma through the crust, via magma chambers to eruption are inaccessible to direct observation and hence poorly understood. Thus Jaggar [23] reported the results of temperature measurements of the Kilauea boiling lava lake surface to be roughly $1140^{\circ} \mathrm{C}$, with a depth of $131 \mathrm{~m}$ to a depth of zero (when the lake was practically dry), and finding that there was no conduit supposedly connecting the lava lake with the mantle, only fractures. However, the lake somehow received its energy from the mantle. The same results were encountered by Tazieff [24] when Nyiragongo Volcano in Zaire empted in 1977 during an earthquake the bowl of its crater, flooding during 25 minutes 2000 hectares with $1100^{\circ} \mathrm{C}$ basanite lava pouring forth through fractures that suddenly opened in the lava lake. There were no vertical conduits with convecting liquid magma in the empty crater, and not even a large but empty one, only fractures. Similar results were obtained lately [25], using a joint local and teleseismic earthquake P-wave seismic inversion revealing a basaltic lower-crustal magma body and a few $\mathrm{km}$ thick fractured rock that provides a magmatic link between Yellowstone mantle plume and the previously imaged upper-crustal magma reservoir [25, figure 3 and figure 4].

Huang, H.H., Lin, F.C., Schmandt, B., Farrell, J., Smith, R.B. , Tsai, V.C. [25] state that "seismic images depict characteristics of the entire Yellowstone magmatic system from the upper mantle to the crust in which the west-northwest-dipping plume is the magmatic source that generates the mafic/basaltic partial melts that intrude into lower crust to produce more silicic magma, and then intermittently ascend to shallower depth to form the rhyolithic reservoir at depths of 4 to $14 \mathrm{~km}$ beneath the Yellowstone caldera." However, there are no conduits, connecting mantle plume with the upper basaltic and rhyolitic partial melt reservoirs ( $2 \%$ to $9 \%$ of partial melts estimation) as they are separated by $10 \mathrm{~km}$ and $5 \mathrm{~km}$ thick solid rocks containing dikes and fractures. Partial melts cannot pass through cooler few-kilometers-thick barriers of solid rock without an additional influx of energy provided by reactive gases of the mantle plume. For an example of a gas-energy-release by volcano, the 1815 Tambora eruption blew out (among ash and other chemicals) about $52 \times 10^{6} \mathrm{t}$ of sulfuric acid [26], whose synthesis from primary elements could produce energy equivalent to 96 megatons of TNT. The synthesis of $50 \times 10^{6} \mathrm{t}$ of water from a hydrogen-oxygen mixture ("detonating gas") could produce the energy equivalent of 150 megatons of TNT. Erupted chlorine and fluorine gases mix with the water-steam and form acids. The processes of mass and energy transport, described in [2] [3] and in part herein, are self-focusing, depending on the kinetics of these processes and on the matter-viscosity conditional to phase transition and the movement of shock-wave fronts (see beneath). Self-focusing causes a 
decrease in the internal energy of an open system, which is well known in physics and electrochemistry.

The proposed sequence of mutually induced reactions supplies active reagents and highly energized mantle gases to the lithosphere, where their heat-producing reactions melt the asthenosphere and the upper mantle. The melting and accompanying explosions bore conduits and chambers for generated magma which rise through the brittle rocks and provide the energy for igneous activity and volcanic eruptions with all their manifestations. We regard the "tectonic earthquake" as a chain reaction, as cumulative chemical explosions of active compounds, which result in multistage degassing with the mantle of $\mathrm{He}, \mathrm{H}, \mathrm{O}$, $\mathrm{H}_{2} \mathrm{O}, \mathrm{SO}_{2}, \mathrm{CO}_{2}$ etc. These explosions are often accompanied by hypocenter movements along faults and fault-zones rising from higher to lower pressure, up to the very shallow depths (volcanic chamber). The volcanic tremor does not accompany an eruption but participates in its generation by series of heat-producing explosions (see Chapter 4).

The main processes of mass-energy-transfer include the following:

1) Cold nuclear synthesis (fusion reactions), which are accompanied by generation and release of energy, where ${ }^{3} \mathrm{He},{ }^{4} \mathrm{He},{ }^{3} \mathrm{H}$ and earth neutrinos [27]-[33] dissociate "stable" compounds and catalyze new fission and fusion reactions.

2) The natural fission nuclear reactors with fast neutrons on the boundary of Earth's solid/liquid core, and possibly, liquid core/mantle [34] [35] [36]. The capacity of those reactors depends on the Sun-Axions flow-intensity [37]. Solar activity cycles modulate radiogenic processes in the Earth that promote the cyclic seismic and volcanic activity of the planet.

3) Convective transport of the hydrogen, hydrides, and other gas-liquid substances by plumes which include:

a) Possibility of the cold fusion during this transport;

b) Step by step transport of energy (dissociation of compounds due to thermo-catalytic activity of rock on the surface which may be during tidal wave motion - reaction on the front of the shock waves);

c) Thermo-diffusional separation of the helium, hydrogen and oxygen, chlorine, fluorine, etc.

4) The formation of cracks and porous mantle structures which provides an accumulation of the separate potentially active matter. This is possible due to the "brittle" behavior of the solid, semi-liquid and liquid matter at high velocity of loading. The velocity of the loading increases with increase of channels transmissivity which simultaneously decreases temperature, pressure and solubility of hydrogen and helium in the mantle matter; gas fills pores and cracks. Brittle solid properties of the mantle matter at high velocity of loading are favorable to the formation of the block structure of the mantle and self-focusing of the chemical, thermochemical and electrokinetic processes on the block boundaries.

5) An earthquake future center has a relatively large volume which is filled by active substances due to diffusion through the mantle, convective and similar to 
airlift transport by plumes and injection effect, which provide enriching of plume matter by active substances from the surrounding mantle. This process may include substances, which are produced by catalytic processes on the boundary of the plume-mantle due to shock waves, thermo-catalysis, and electrochemical reactions (piezoelectricity and electrokinetic phenomena). Each type of chemical chain-reaction explosion has a specific rate of detonation and critical volume-cross-section which causes self-ignition and propagation.

6) The gradients of surface potentials (upper versus bottom surfaces of cracks, size of the rocks, gradients of temperature and stress-piezoelectric phenomena, local rate of stream and sedimentation) contribute to a separation and accumulation of possible reagents.

7) Oversaturation of the earthquake hypocenter by defects and active substances leads to joining together of the micro-cracks and formation of the critical size chambers. Before the main earthquake shock relatively small explosions (foreshocks) are often observed. Energy of these explosions will be absorbed by the surrounding matter and structures. Endothermic processes of the dissociation or splitting of the compounds of hydrogen, oxygen, sulfur and others are the natural way of fast absorption of energy and preparation of the major earthquake.

8) Enlargement of the bigger critical cavities and cracks are accompanied by formation of the following currents:

a) Electrochemical processes of dissolving and transportation of matter through growing cracks (Glikman effect).

b) Electrochemical processes of oxidation and reduction of the mantle compounds due to the gradient of temperature and rock surface potentials.

c) Electrokinetic processes of flow of the melts and melt-based suspension and gas bubbles.

d) All these processes are accelerated by shock waves which are created by tidal waves or minor explosions.

e) Part of the released energy may be stored as active substances in surrounding zones of the mantle and/or as a zone of the increased crack concentrations as a precursor of aftershocks.

9) Combination and linking together of the relatively small explosions by mutual induction is possible at critical concentrations of cavities and cracks. This causes a chain reaction of explosions - the major earthquake.

10) Part of the energy of those processes will be stored in the mantle as clusters of cracks and cavities close to blocks boundaries. These ill became natural centers of accumulation of hydrogen, helium and active substances which are transported by plumes and by diffusion in the preparation stages of the next earthquake.

This comprehensive model may help find solutions to practically all enigmas and questions related to the lack of a plausible energy source for the mantle plumes, earthquakes and volcanic eruptions. 


\section{The Hypothetical Physical Chemistry of the Earthquake-Hypocenter - Volcanic-Eruption Preparation as a Basis for Their Prediction}

The possible solution of the short-term earthquake prediction problem is proposed herein based on the analysis of the physicochemical processes as participants in earthquake preparation and on the characteristic rate of reflection of these processes on the Earth's surface. This proposed solution provides a way of selecting a complex of reliable earthquake precursors using the Inverse Problem Method for earthquakes which will occur in the region around the monitoring point (radial distance $\approx 700 \mathrm{~km}$ ) in the next seven day period [1].

Semenov already declared [38] that the trains of chemical explosions are chemical branched chain-reactions. This declaration is supported by a comparison of seismograms from earthquakes and nuclear explosions where the complexity of natural events (earthquake) is higher than that of artificial events (explosions). Micro- or macro-foreshocks are forerunners of the major shock. Natural earthquakes are more complex than nuclear explosions at teleseismic distances and the difference between them is obvious. This difference is observed very clearly in the relationship of solids to surface-wave amplitudes [39]. The nuclear weapons test is just an explosion sometimes followed by aftershocks, whereas earthquake is the superposition of the totality of explosions which are distributed in space and time.

Prerequisites for the chemical explosions are the critical concentrations of reactants and their ratio which depends on PT-conditions [38] [40] [41]. The critical concentration of the reactants and critical size of the explosive substances cluster is the first necessary condition of the local explosion [42]. The possibility of explosion propagation (or detonation) to other clusters depends on the distance between clusters or on the cluster volume concentration. The critical or more than critical concentration of ready to detonation volume of explosive substance clusters is the second condition of earthquake. Too large a distance between clusters limits propagation of detonation possibility due to the local explosion's energy being absorbed by the surrounding matter. This absorption causes local heating of matter and formation of the chemically active substances [43].

Relatively small concentrations of the explosive clusters before an earthquake produce foreshocks, which prepare an earthquake's major shock. Combustion of most of the clusters during the earthquake process decreases their concentration and generates aftershocks, (which take part in the rising hypocenter) and cause the relaxation of the surrounding matter.

Formation and accumulation of the explosive substances cluster, and preparation of the earthquake, is a totality of process. The hypocenter is an open thermodynamic system which uses all of the possible degrees of freedom. This system is non-linear due to a principally different rate of separate processes: The diffusion and filtration of molten matter through porous rock and cracks, heating and cooling, and stress and strain flow. An earthquake may be described as a 
bifurcation, which returns part of the mantle - lithospere system to their main trajectory of development, which corresponds to minimal internal free energy of the system and maximal rate of entropy production in the macrosystem. In the comparison of possible energy sources for earthquake and volcano eruption, consideration must be given to the fact that from all the known natural means of transmitting the needed energy, its transportation by chemical reactions is $2-3$ fold more effective than the convective transportation by mass of the heat-carrier. The following possible reactants participate in earthquake explosion: hydrogen - oxygen; hydrogen - halogens; hydrogen - sulfur; alkanes (methane, etc.) - oxygen; alkanes - halogens; alkanes - nitrates, etc.

Explosive substances are produced and accumulated due to the energy which is released in the earth's core, mantle, and lithosphere, by the five main sources listed below [1]:

1) The cold nuclear synthesis (fusion reaction) is an important source of energy, and a source of additional flow of ${ }^{3} \mathrm{H},{ }^{3} \mathrm{He},{ }^{4} \mathrm{He}$ and earth neutrinos as shown by experiments of cold fusion on boundaries $\mathrm{Fe}-\mathrm{Ni}$ and melt of aluminum silicates, iron and nickel compounds and oxides eutectics [27]-[33].

2) The natural fission nuclear reactors with fast neutrons on the boundary of Earth's solid/liquid core, and possibly, liquid core/mantle [34] [35] [36]. Capacity of those reactors depends on the Sun-Axions flow-intensity [37].

3) Tidal waves cause dissipation of energy and stimulate the physical-chemical processes in the Earth's core, mantle, lithosphere, and in the near-to-earth side of the Moon's interior [44].

4) Gravitational differentiation promotes the solid core formation and plumes activity [45].

5) Earth's degassing of hydrogen and helium [2] [3] [45] [46] [47], is the main source of energy of the mantle plumes, earthquakes and volcanic eruptions and generate anomalies of these gases in the vicinities of active faults. Earth's degassing forms a halo of hydrogen and helium surrounding our planet and comprising its exosphere. Physical-chemical processes are the most effective way of transformation, transportation, and accumulation of energy into the earthquake hypocenter or volcanic chamber.

Total heat losses of the earth are $46 \pm 3$ TW [48], including about 20 TW of the released radiogenic heat. According to neutrino flow measurements radiogenic component in heat losses would be near $19.9 \pm 9$ TW [27] [36], or 30\% $50 \%$ of the global internal heat-flow of the Earth. Heat from the core is about 8 TW [[48], table 11]. Heat flow from the convective mantle, including gravitational differentiation and degassing, is about 39 TW ([2] [3] [48], table 11]). Average annual energy of earthquakes is about $0.44 \mathrm{TW}$ and the energy of tidal wave dissipation is about 0.1 TW [[48], table 13]. Total energy of earthquakes and volcanic eruptions is about $1 \mathrm{TW}$, all of which has to be transported and accumulated in hypocenters/volcanic chambers as latent chemical energy. This is the only possible way. 
Heat and radiation produced by the nuclear reactions cause dissociation and increase of reactants temperature, which create thermal currents due to the Seebeck effect. Partial or complete melting of solid matter generates electrochemical processes on phase boundaries and corresponding galvanic currents. Local heating increases the local pressure and accelerates the movement of semi-melt or melt matter through porous rock and cracks, creating the streaming potential, sedimentation potential, and corresponding currents. Temperature gradient of the heat flow causes electric gradient or electrode potentials on phase boundaries, which create electrophoresis and electroosmosis. Hydrogen, oxygen, sulfur, halogens, carbon, nitrogen, aluminum, and alkaline metals are possible participants in the energy transport due to their chemical activity. The presence of helium increases the flexibility and rate of stream of solids and melts [46] [49] [50]. Moreover, hydrogen, lithium and boron may take part in nuclear fusion reactions [27] [28] [30] [31] [51] [52]. Movement of the matter creates triboelectricity [53] due to friction between boundaries of the mantle-fragments and of gas-liquid plume and mantle, and also promotes electrokinetic phenomena (electrophoresis and electroosmosis).

\section{Sun-Moon Tides as the Most Important Triggers for Earthquakes}

Tidal waves cause dissipation of energy in the mantle and lithosphere, periodic stress - strain waves create peristaltic effect and increase the rate of the rising of plume matter. Velocity of tidal waves in the lithosphere $(460 \mathrm{~m} / \mathrm{s})$ is higher than the critical rate of brittle cracks propagation, so that cracks are generated. Cracks and cavities are filled by melt, steam, gas, suspension, etc. The Coexistence of the liquid and solid phases provides "adiabatic" heat transport with maximal efficacy. The latent heat capacity during a phase transition is two orders of magnitude higher than for a mixed liquid and solid phase due to the latent heat of the heat transition ([1], references there). Therefore the solid-liquid state is thermodynamically preferable for the mantle matter and for the earthquake hypocenter heat transport.

Most of these processes are accompanied by electromagnetic phenomena. The rate of the magnetic field propagation is $\sim 300,000 \mathrm{~km} / \mathrm{s}$ which means that geomagnetic signal approaches the Earth's surface without any delay. However, the time taken for relaxation processes, for creating electrical currents, and for changing the local geomagnetic field is much longer than that of magnetic field propagation. Rate of detonation at atmospheric pressure varies from 3 to 11 $\mathrm{km} / \mathrm{s}$ (more than the velocity of sound) whereas the rate of the longitudinal and transverse waves in the solid mantle varies from 8 to $13.5 \mathrm{~km} / \mathrm{s}$ for P-waves and from 4.5 to $7 \mathrm{~km} / \mathrm{s}$ for $\mathrm{S}$-waves. The rate of all other processes may be much smaller. For example, the rate of plume matter movement, of diffusion or filtration through fractured or porous rock, may be very low also. Thus, processes of earthquake-hypocenter preparation comprise a multi-parametric non-linear 
system, which compensates differences in times of response or relaxation of different processes by bifurcation (explosion).

Only electromagnetic phenomena and compressional waves reflect the processes of earthquake-hypocenter preparation in the real time. All the rest of the precursors related to mass-heat transport arrive at the Earth's surface with a delay depending on the depth of the hypocenter and of the local geophysical conditions reflecting the rate of reactants accumulation in the hypocenter. This means that the probability of earthquake can be estimated in accordance with the alterations of the maturing earthquake hypocenter susceptibility to the tidal waves. Our concern is with the alterations of the compressibility of the hypocenter medium with the passage of tidal waves, possible changes of the forms of tidal waves, variations in infrared radiation, and release of gases during tidal waves passage and correlation of these processes with the condition of the ionosphere. The Ionosphere is influenced by the electromagnetic fields of the hypocenter and of its feeder area, and also by the processes of brittle cracks propagation and generation which can be accompanied by the radio-frequency electromagnetic radiation and outbursts of high energy particles.

The monitoring system has to use parameters with a characteristic time of response equal or shorter than the duration of hypocenter matter relaxation. Moreover, the time it takes for measurement of these parameters has to be shorter than the time of earthquake preparation. Time and the rate of the processes involved are variable and may accelerate toward earthquake or bifurcation. It means that a relatively short-time reliable prediction may be based only on monitoring the changes of the electromagnetic fields and viscous-elastic waves as response to tides only [1].

For the longer time prognosis, other reliable precursors have to be included.

\section{Volcanic ("Harmonic") Tremor}

Spasms of volcanic ("harmonic") tremor have always been noticed as a part of the preparation of the volcanic eruption and are usually explained by the movements of magma in the volcanic conduits, the venting of volcanic gases from magma, or both. The tremors are described as a type of continuous, rhythmic ground shaking which is different from the discrete sharp jolts characteristic of earthquakes and explosions, and characterized by special seismic signatures (Figure 4). However, very often tomography of the underbelly of a volcano shows an absence of any major conduit, where the solid rock contains only dikes and fractures passable only to the gaseous matter that is the feeder of its activity (e.g. Yellowstone, Chapter 2). We think that volcanic tremors (and shallow earthquakes) are generated by the reactive "volcanic" gases streaming into the volcanic chamber ahead of magma.

As is usually observed, the harmonic tremor is accompanied by the increasing activity of tectonic-like and shallow volcanic earthquakes. The generating them movement of the medium includes phase transition through parallel channels or local resistances (e.g. liquid - gas - liquid) can lead to pulsations (cavitation), 


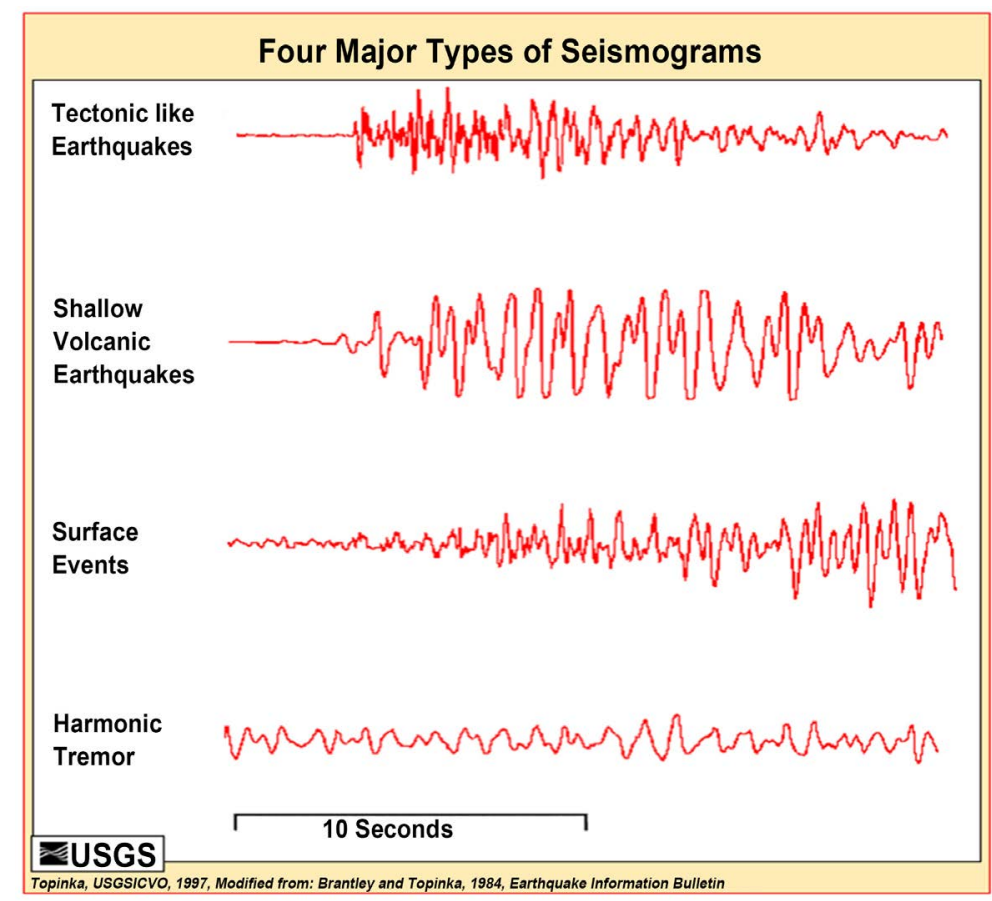

Figure 4. Four major types of seismograms, or seismic signatures, from https://en.wikipedia.org/wiki/Harmonic_tremor.

since completely different mass flows correspond to the accompanying pressure drops and rises. Pulsations of flows cause vibrations which increase rate and transport of the matter. There is possible an interrelated increase of tremor and volcanic chamber (hypocenter) preparation and enhancement of instability. Volcanic tremors can be explained by the following processes: a) pulsation caused by adiabatic expansion (drosseling) of reactive gases exiting from fractured rocks into a larger space of a volcanic chamber ( $\mathrm{H}$ and $\mathrm{He}$ do not cool when expanding under Earth's internal temperatures); b) when (if) volcanic chamber energy is supplied by the reactive gases (mainly, the mixture of $\mathrm{H}$ and $\mathrm{O}$, known as detonating gas) at an inadequate rate, or of concentration less than critical for explosion, they may be repeatedly (pulsatory) concentrated to the critical mass by adsorption at the interfaces; c) oscillations of the Belousov-Zhabotinsky type of chemical reactions, where as a result of minor explosions and a related buildup of pressure, parts of compounds dissociate absorbing explosion energy. Products of dissociation bounce apart owing to their mass differences and electrophoresis and concentrate back preparing the next explosion (explosions); d) by solution or extraction of $\mathrm{Cl}, \mathrm{Br}, \mathrm{F}$ and other potential reactives from the volcano's rocks, in this case the rate of tremor explosions will be dictated by the rate of reactants extraction. These processes are characterized by a very high intensity of energy generation from the internal sources and their quick repetition is conceivable when reactions between some of the gases begin as combustion and develop as a chemical chain reaction culminating in the explosion. 
Active reagents-free atoms and radicals - in the course of that chain development also react with molecules of the initial gases and with the end products, generating new active centers. The mixture of oxygen and hydrogen explodes when hydrogen concentrations reach between $6 \%$ and $95 \%$ (volume). When even small amounts of water vapor are present, explosion occurs at a temperature of about $600^{\circ} \mathrm{C}$. The water is a catalyst accelerating explosive reactions a thousand-fold. Most of water steam expelled by volcanoes is a product of those reactions, and the source of most of the hydrogen and oxygen are from the mantle plumes as a main part of Earth's degassing [2] [3] [26].

\section{Regional Earthquake Triggering Other Earthquakes and Enhancing Volcanic Eruptions}

Answering the question whether a regional earthquake can trigger another earthquake at a distance of thousands of kilometers [[12], p. 1429], or enhance volcanic activity, requires a systematic measure of volcanic activity. One such measure is heat flux. Donne et al. [14] used the availability of a satellite derived heat flux inventory for global volcanism for the exploration of how earthquakes and volcanic activity may be linked. Examination of 7 years of global volcanic heat flux data revealed 37 volcanic responses to regional earthquakes. Each response was expressed by an increase in heat flux within 1 - 21 days of the triggering earthquake. Of these responses, 22 (59\%) occurred at volcanoes where activity was ongoing at the time of the earthquake with the remaining 15 cases recorded at volcanoes that started to erupt only after the earthquake had occurred. A three-stage heat-flux response was defined firstly by recording a steady level of low-heat fluxes or no fluxes at all prior to an earthquake. Secondly, a sudden but short-lived increase in heat-flux shortly after the earthquake, and the third, the response was completed by a return to low heat-fluxes of the pre-earthquake level. The authors of reference [14] found that whether a volcano responds depended on the earthquake magnitude (higher magnitude generated longer responses), distance to the epicenter and orientation of the earthquake fault, and is within $30^{\circ}$ with respect to the volcano azimuth. Of the 7 global major increases of seismic energy recorded during 2000-2006, 4 were followed by a global volcanic heat-flux increase where the largest response (300\% increase) followed the greatest 2004 Sumatra earthquake, $M_{w}=9.3$. Within 21 days of this event responses were realized at 4 volcanoes: Kilauea (delay 1 day, distance $=$ $12,000 \mathrm{~km}$ ), Anatahan (Mariana Islands; delay = 11 days, distance $5800 \mathrm{~km}$ ), Popocatepetl $($ Mexico; delay $=13.2$ days, distance $=17,000 \mathrm{~km})$, and Kluchevskoi (Russia Kamchatka; delay $=21$ days, distance $=8300 \mathrm{~km}$ ). However, there were many cases where erupting volcanoes in the vicinity of a regional earthquake did not respond, and of the seven events of major seismic energy increase, two were not associated with a global heat flux response. This selectivity in response can be explained, possibly, by the existence of the Earth's resonance system, which results from interference of the voluminous and surface waves pass- 
ing through lithosphere, mantle, and core, contemporaneously with surface-waves passing through the lithosphere and the upper mantle. For the prognoses of response, additional research will need to be done studying the quality of energy-relation links which is inversely related to the resistance or to the energy dissipation to the surroundings. The energy-relation links also can work as triggers of the enormous peristaltic pumps, working through the earthquake mantle plume - liquid core - mantle plume of the rejuvenated volcano. In any case the documented by authors [14] facts evidence the incredible rate of the energy transfers through the internal channels of our Planet.

\section{The Case of the 1980 Eruption of Mount St. Helens}

As we have already noted (Chapter 2) earthquakes precede and accompany volcanic eruptions, but not every earthquake culminates in a surface eruption. As an example of the latter case where the main earthquake hypocenter rises to near-earth-surface and transforms into volcanic eruption, we shall cite the well-studied 1980 eruption of Mount St. Helens.

Facts and dates are taken from information supplied by the Mount St. Helens National Volcanic Monument, including some films, and publications with our commentary shown in parentheses.

March 16-20-series of very small, $\mathrm{M}<3$ earthquakes; (foreshocks).

March 20-Magnitude 4.2 earthquake; (the major deep preliminary shock, which opened a part way for the magma gas-liquid stream from asthenosphere to the anomalous zone between about 4 and $14 \mathrm{~km}$ below sea level (BSL), characterized by high seismic $V \mathrm{p} / V \mathrm{~s}$ ratios and low $V \mathrm{p}$ values, is inferred to represent an Upper Crustal Magma Reservoir. Maximum melt fractions of 10\% $12 \%$ are inferred at $4-6 \mathrm{~km} \mathrm{BS} \mathrm{[54]} \mathrm{[55]} \mathrm{[56].} \mathrm{This} \mathrm{earthquake} \mathrm{marked} \mathrm{the} \mathrm{be-}$ ginning of the "second boiling process of magma that had resided in the reservoir for centuries to millennia" [56]).

March 20-25-increase of small earthquakes activity; (aftershocks).

March 25-27-174 shocks with $M>2.6$ accompanied by many hundreds of smaller earthquakes; (foreshocks, forerunners of the major shock of the March 27).

March 27-Thunderous explosion, ash and steam, ash column rose to about 6000 feet above the volcano. The initial explosions formed a 250 -foot-crater within the larger, pre-existing summit crater, and new fractures broke across the summit area; (the major shallow preliminary earthquake beneath the volcanic chamber that marked the opening of the conduit and the beginning of forceful intrusion of gas-liquid magma into the volcanic chamber. There could not be "phreatic steam-blasts", the cooler water existing at that depth's pressure could not have penetrated the hotter than their boiling temperature rocks or partially melted magma reservoir, it would have evaporated previously. (Anybody tried to put some water into the red-hot iron?) Steam of the explosion was very probably generated by the explosions of the magmatic detonating gas, a mixture of hy- 
drogen and oxygen.)

March 27 - May 18-Ejection of ash and steam in bursts lasting from a few seconds to tens of minutes. Ash derived from the 350-year-old summit dome, shattered and pulverized by phreatic (steam-blast) processes driven by the explosively expanding, high-temperature steam and other gases. No magma was present during initial eruptions. Intense earthquake activity persisted at the volcano during and between visible eruptive activities [[54] p. 7]. (Periodical steam-bursts and mini-explosions could be forerunners of harmonic tremor. The emission of flaming gases from the new crater, visible in the evening light to many observers, was a remarkable evidence of magmatic gas-eruption).

March 31 - May 16-Occasional spasms of volcanic tremor, a type of continuous, rhythmic ground shaking different from the discrete sharp jolts characteristic of earthquakes. Visible eruptive activity ceased temporarily in late April and early May. Small steam-blast eruptions resumed on May 7, continued intermittently for the next several days, and ceased again by May 16. During this interval, the forceful intrusion of magma into volcano continued with no respite, as was shown by intense seismic activity and visible swelling and cracking of the volcano; (volcano was not closed hermetically; see also Chapter 5).

The swelling was measurable and affected a large area on the north face of Mt. St. Helens. This area became known as the "bulge", the initial growth of which probably began during the first eruption (March 27) or perhaps even a few days before. Through mid-May about 10,000 earthquakes were recorded. The earthquake activity was concentrated in a small zone less than 1.6 miles directly beneath the bulge on the north flank of Mount St. Helens. By May 12 certain parts of the bulge near the summit were more than 450 feet higher than before the magma intrusion began. Repeated measurements begun in late April with precise electronic instruments that shoot a laser beam to reflector targets placed on and around the bulge showed that it was growing northward at an astonishing rate of about 5 feet per day. The movement was predominantly horizontal - clear evidence that the bulge was not simply slipping down the volcano's steep slope. As the bulge moved northward, the summit area behind it progressively sank, forming... graben. These changes in the volcano's shape were related to the overall deformation that increased the volume of the mountain by 0.03 cubic miles by mid-May. This volume increase presumably corresponds to the volume of gas-liquid magma that pushed into the volcano and deformed its surface [[54] p. 8].

A separate volatile phase was likely accumulated in magma beneath Mount St. Helens prior to the climactic eruption. The highly volatile contents likely supported magma ascent, where the rise of magma appears to have been rapid during a period of less than two months. (10,000 earthquakes-explosions busy melting local rocks and heating melts for the "second boiling" in the volcanic chamber; accumulation of reactive gases and explosive clusters during preparation stage of the major earthquake hypocenter only 1 mile beneath volcano!) 
About 20 seconds after 8:32 a.m. PDT May 18, apparently in response to a magnitude-5.1 earthquake about 1 mile beneath the volcano, the bulged, unstable north flank of Mount St. Helens suddenly began to collapse. What happened within the next few seconds was described by geologists Keith and Dorothy Stoffel, who at the time were in a small plane over the volcano's summit. Among the events they witnessed, they... "noticed landsliding of rock and ice debris inward into the crater... the south-facing wall of the north side of the main crater was especially active. Within a matter of seconds, perhaps 15 seconds, the whole north side of the summit crater began to move instantaneously. The nature of movement was eerie... The entire mass began to ripple and churn up, without moving laterally. Then the entire north side of the summit began sliding to the north along the deep-seated slide-plane, and in another few seconds a huge explosion blasted out of the detachment plane. We neither felt nor heard a thing, even though we were just east of the summit at this time.” [[54] p. 11] (That was the opening of the $\mathrm{M}=5.1$ earthquake-hypocenter on the depth of $1.0-1.6$ miles! The major chemical explosion of the magmatic gases).

This explosion produced a lateral "pyroclastic density current". Most geologists refer to it simply as "the blast", though some prefer the term "surge", contending that it was not really an explosion. The blast cloud accelerated as it spread, drawing heat energy from the fragmented magma it contained. Inside the cloud were ash, pumice, lava blocks, snow, ice from the overlying glaciers, tree fragments, soil swept from the ground, and boulders as big as cars. It expanded at speeds of hundreds of miles per hour, but in a particular way... The avalanche created an amphitheater-shaped gouge in the mountain, and this gouge channeled the blast to the northwest, north and northeast. ... The front of the cloud was magnificent. It was like an immense oncoming waterfall with great blocks of earth and ice cascading from far overhead." [[57] p. 147].

According to [[54] p. 15] "Calculations have shown that the blast's initial velocity of about 220 miles an hour quickly increased to about 670 miles an hour... the near-supersonic lateral blast, loaded with volcanic debris, caused widespread devastation as far as 19 miles from the volcano. The area affected by the blast can be subdivided into three roughly concentric zones: 1) direct blast zone... averaged about 8 miles in radius, an area in which virtually everything, natural or manmade, was obliterated or carried away. For this reason, the zone also has been called the "tree-removal zone". The flow of the material carried by the blast was not deflected by topographic features in this zone (Figure 5). 2) Channelized blast zone, an intermediate zone, extended out to distances as far as 19 miles from the volcano, an area in which the flow flattened everything in its path and was channeled to some extent by topography. In this zone, the force and direction of the blast are strikingly demonstrated by the parallel alignment of toppled large trees, broken off at the base of the trunk as if they were blades of grass mown by a scythe. This zone was also known as the "tree-down zone." 3) Seared zone, also called the "standing dead" zone, the outermost fringe of the impacted 


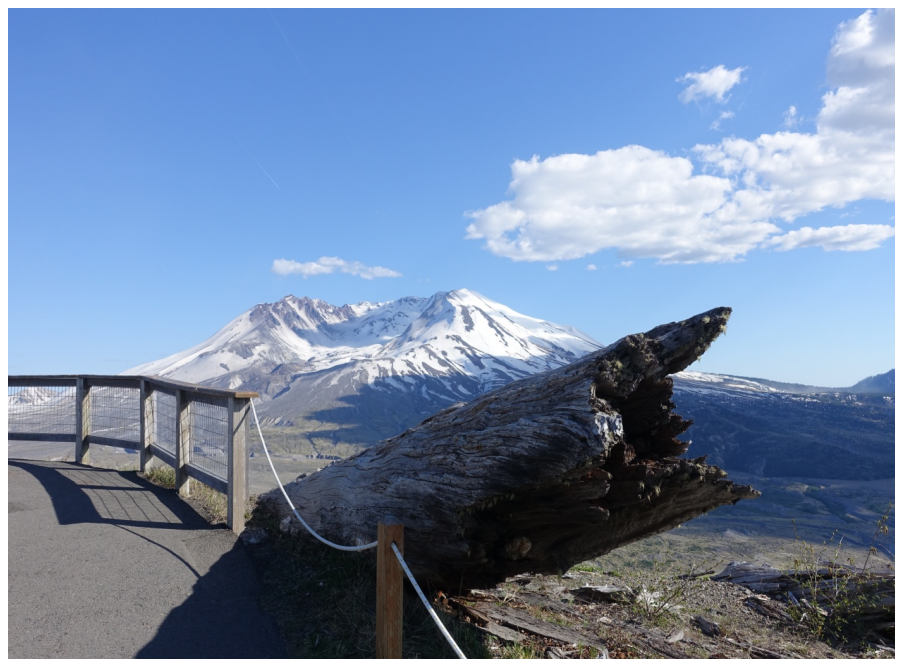

Figure 5. View of Mount St. Helens from the Mount St. Helens National Volcanic Monument area, the direct blast, or the "tree-removal zone.” (photograph by E. Gilat-Feigenberg, May 2017.)

area, a zone in which trees remained standing but were singed brown by the hot gases of the blast (Figure 6).

\section{Discussion about the mechanism of the 1980 Eruption of Mount St. Helens}

Our (the authors) conclusion differs from that of the most of the USGS geologists (e.g. [54]): earthquake triggered landslide-avalanche that "triggered the almost instantaneous expansion (explosion) of high-temperature - high-pressure steam present in cracks and voids in the volcano and of gases dissolved in the magma that caused the bulge of the cryptodome. The abrupt pressure release, or "uncorking", of the volcano by the debris avalanche can be compared in some ways to the sudden removal of the cap or a thumb from a vigorously shaken bottle of soda pop or to punching a hole in a boiler tank under high pressure." [[54] p. 14].

From the short description of the preliminary stages of the Mt. St. Helens May 18, 1980 eruption (above) is clearly seen that the "high pressure boiler tank" was "punched" by the volcano's preceding eruptive activity ("The ash blown out between March 27 and May 18 was derived entirely from the 350-year-old summit dome, shattered and pulverized by phreatic (steam-blast) processes driven by the explosively expanding, high-temperature steam and other gases. No magma (molten rock and contained gases) was tapped during initial eruptions." [[54] p. 8]. In this connection the 1980 eruption of Mount St. Helens was not different from the Tambora, 1815; Krakatoa, 1883; Pinatubo, 1991; and many other eruptions, where the main explosions came from the open chambers and were generated by reactive volcanic gases where hydrogen with some oxygen (detonating gas producing water steam) were dominating ([2] [3] references there). Mount St. Helens May $18 \mathrm{M}=5.1$ super-shallow high-intensity earthquake hypocenter 


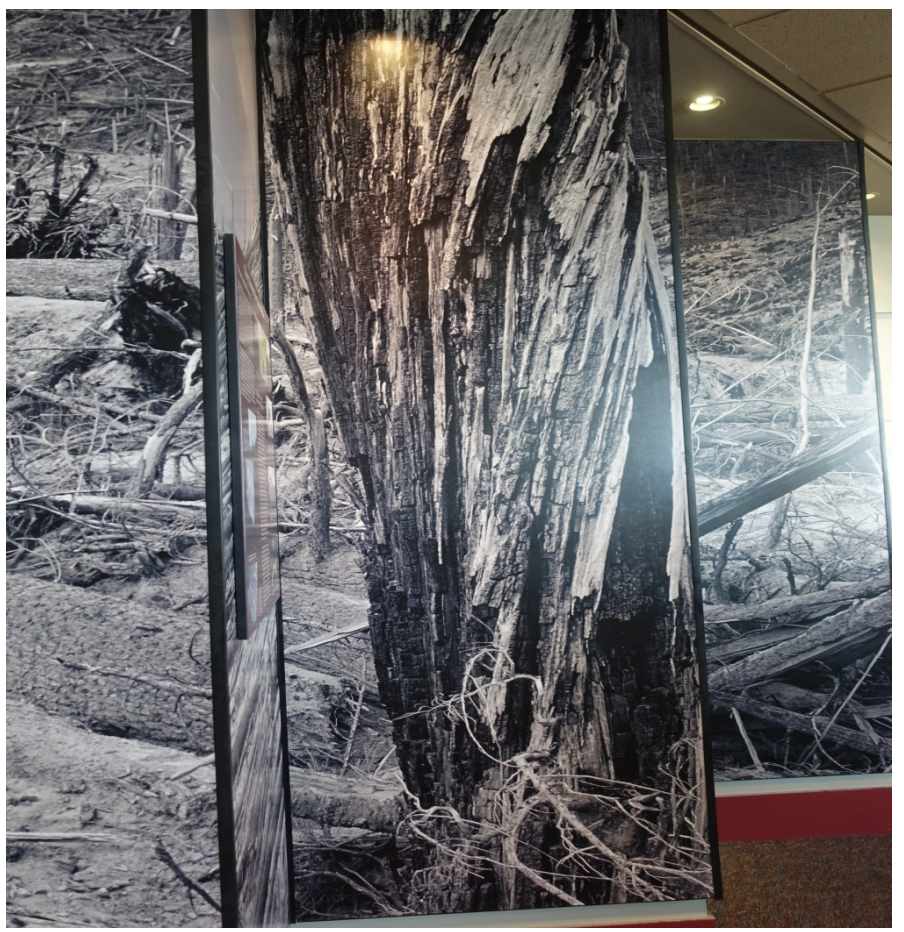

Figure 6. The singed brownish-black tree from the "standing dead" zone from the Mount St. Helens National Volcanic Monument's training exhibition (photograph by A. Gilat).

culminated in a monstrous surface explosion-eruption. The eruption triggered phenomenon was a single 9 hour long process where the chemical reactions did not stop acting during the "near-supersonic" lateral blast, which caused widespread devastation and a seared zone as far as 19 miles from the volcano. It was a chemical explosion of magmatic gases and not a steam blast; it is not surprising, then, that "major inflammation was prevented by lack of oxygen consumed in oxidation"; steam is nonflammable and can't consume oxygen. This process continued generating an eruptive column to an altitude of more than 12-miles with at least 17 separate pyroclastic flows. We do not have any doubt that the beginning of energy transmission from the nearest branch of a mantle-plume and its accumulation which prepared this eruption, was marked off by its deep forerunner magnitude 4.2 earthquake on March 20, 1980. This was preceded by smaller foreshocks, following aftershocks, and small-scale eruptive activity. The shallow forerunner major quake of March 27, was followed by harmonic tremors and a series of small earthquakes (the phase of energy accumulation) in late April-early May, and from May 16 up to the tens-seconds-long main explosion (which is comparable to the length of $M=8-9$ great earthquake) of the earthquake-eruption of May 18 and its further developments. All together it was a single, combined physical-chemical process extending over a two month period, which released on May 18, 1980, 24 Mt. of thermal energy, 7 by blast, with the rest through the release of heat (https://pubs.usgs.gov/fs/2000/fs036-00/). That's about half of the energy released by Tsar Bomba-the largest thermonuclear 
weapon ever tested. From where can such an immense amount of energy come from? From injection of magma into an upper crustal reservoir? Could this magma rise since March 20 into an edifice without generating seismicity deeper than $2.5 \mathrm{~km}$ beyond the volcano? It is very, very doubtful. Only reactive gases were able to cope with such a problem-they succeeded with the release of 2.7 Gigatons of energy-equivalent during the 1960 Valdivia earthquake (Chile), without any magma involved [3].

\section{Conclusions and Description of the Proposed Monitoring of Reliable Precursors}

All of the described above for Mount St. Helens, 1980 is a very typical seismic activity including inflow of volcanic gases and flames of the burning gases which are usually marked by enrichment in ${ }^{3} \mathrm{He}$, perturbations in ionosphere, high heat-flow, and electromagnetic field fluctuations (Chapter 5 and [1]). Most of the seismic processes are preceded by much publicized ground deformations and fluctuations of ground water levels and chemical composition of the volcanic gases. However, the latter ones do not provide a clear forecasting possibility.

Among the possible changes of the state of the volcanic chamber are their internal pressures, solid-liquid to gas ratio, average density, intensity of the chemical and electrochemical reactions, etc. that would cause a change of its compressibility and domain response to tidal waves. Its response may be observed as a change of shape of the surface tidal waves and perturbation of the Earth magnetic fields and ionosphere. The multiparametric analysis may improve reliability and accuracy of prediction. So, we will briefly review the additional "hottest" methods as follows.

Paonita et al. [11] described their success with a high resolution 12-yr-long time series of ${ }^{3} \mathrm{He} /{ }^{4} \mathrm{He}$ ratio measurements in gases emitted from peripheral vents around the Mount Etna volcano (Italy), which revealed variations with strong correlations over both time and a broad spatial scale. The main eruptive episodes are preceded by increases in ${ }^{3} \mathrm{He} /{ }^{4} \mathrm{He}$, making this ratio a unique tracer for monitoring volcanic activity. Sano et al. [58] wrote that this tracer was the only one capable of providing clues about increasing activity of the Mount Ontake eruption in Japan over a timescale of years. This approach is widely applicable, because time-dependent $\mathrm{He}$-isotope mixing between primitive and more radiogenic end members appears to be common in active volcanoes [59]. Paonita et al. [11] recommended a long-lasting time series with sufficiently frequent samplings and high precision ${ }^{3} \mathrm{He} /{ }^{4} \mathrm{He}$ measurements in air-free volcanic gases, "since even small isotope variations (fractions of 1 Ra unit) can reflect important volcanic processes". We have to remind that remarkable correlations between mantle helium-3 concentrations and internal heat-flows, found by many researchers in sea-floor hydrothermal flows since 1970s (e.g. [60]), and numerous subsequent articles (e.g. [61], may be another direct indication for this connection, and highly recommend the ${ }^{3} \mathrm{He} /{ }^{4} \mathrm{He}$ measurements in volcanic gases as a 
valuable indicator for eruption forecasting, together with the direct heat-flow monitoring from satellites.

Donne et al., [14] successfully used for a similar purpose the moderate resolution imaging spectroradiometer (MODIS) sensor flown aboard the National Aeronautic and Space Administration's Terra and Aqua satellites. The MODIS sensors on these two satellites pass over every point on the planet four times a day, allowing detection of thermal anomalies associated with ongoing volcanic activity. The MODVOLC detection algorithm allows automated global hotspot detection in MODIS data and provides a global inventory for volcanic hotspots dating back to February 2000 [62]. Spectral radiance data recovered for hotspots detected by MODVOLC can be converted to heat flux for all terrestrial eruptions [63].

Ouzounov et al., [13] used the M9 Tohoku Japan earthquake of March 11, 2011 related data, retrospectively analyzing the temporal and spatial variations of four different physical parameters outgoing long wave radiation (OLR), GPS/TEC, Low-Earth orbit tomography and critical frequency foF2, and came to conclusion that the joint analysis of atmospheric and ionospheric parameters during the M9 Tohoku earthquake has demonstrated the presence of correlated variations of ionospheric anomalies implying their connection with the monitoring data before the earthquake.

The approach proposed for solving the problem of "how, where and when" of an earthquake's prediction does not except the commonly accepted investigations based on seismology, geology, geoelectromagnetism and JPS data. Presented in ([1] and also in [18] [19] [20] [21]) is a new approach for forecasting of the regional weekly seismic and volcanic activity based on the analysis of the INTERMAGNET geomagnetic field and NASA code for Sun-Moon tides data, Geomagnetic Quake approach. The results are based on the inverse problem method for analysis of the geomagnetic field which instantaneously reflects terrestrial currents in hypocenter. The necessary and sufficient conditions for the existence of a solvable inverse problem are formulated on the basis of the existence of reliable precursors.

So, a real time data acquisition system for researching the reliability of earthquake precursors, formulation, and solution of the overdetermined inverse problem for the magnitude, depth, and coordinates of the epicentre of impending earthquake must include the following additional types of monitoring:

a) Increase of helium 3, 4 and radon surface concentration;

b) Increase of the local heat flows through the earth (and sea) surface;

c) The water-level in boreholes and steam and flames released into the atmosphere;

d) Change of the ionosphere height, conductivity for the radio waves and meteorological conditions;

e) Appearance of low frequency waves in the atmosphere and the Earth's crust, which are not observed by nuclear test monitoring; 
f) Variations in Schumann resonance;

g) An inverse problem could be solved for prediction time ( \pm 2.7 days), magnitude, depth and epicenter coordinates of an upcoming earthquake with 4 parameters.

This method requires at least 4 monitoring points in a region (radial length $700 \mathrm{~km}$ ) to formulate the solvable over determined algebraic system. A combination of the geomagnetic measurements and of the above listed additional reliable precursors is bound to allow getting an over determined algebraic system. The solution of such a multi-parametric system will provide the possibility for estimating an earthquake's magnitude and epifocal coordinates' prediction accuracy and will be very useful for further research of the nature of the tectonic processes.

There are possible current changes of the volcanic chamber state such as: internal pressure, solid-liquid to gas ratio, average density, intensity of the chemical and electrochemical reactions, etc. that would cause a change of its compressibility and domain response to tidal waves. This response may be observed as a change of shape of the surface tidal waves and perturbation of the Earth's magnetic fields and ionosphere. The multiparametric analysis may improve the reliability and accuracy of prediction.

\section{Conflicts of Interest}

The authors declare no conflicts of interest regarding the publication of this paper.

\section{References}

[1] Mavrodiev, S.C., Pekevski, L., Botev, E., Pinar, A., Kikuashvili, G., Vol, A. and Gilat, A. (2018) Study of the Possibility of Predicting Earthquakes. International Journal of Geosciences, 9, 688-706. https://doi.org/10.4236/ijg.2018.912042

[2] Gilat, A. and Vol, A. (2005) Primordial Hydrogen-Helium Degassing, an Overlooked Major Energy Source for Internal Terrestrial Processes. HAIT Journal of Science and Engineering B, 2, 125-167.

http://people.clarkson.edu/ nanosci/jse/B/vol0201B/vg040720.pdf

[3] Gilat, A. and Vol, A. (2012) Degassing of Primordial Hydrogen and Helium as the Major Energy Source for Internal Terrestrial Processes. Geoscience Frontiers, 3, 911-921. https://www.sciencedirect.com/science/article/pii/S1674987112000412 https://doi.org/10.1016/j.gsf.2012.03.009

[4] Reid, H.P. (1910) The California Earthquake of April 18, 1906; the Mechanics of the Earthquake, Carnegie Institute, Washington DC.

[5] Geller, R.J., Jackson, D.D., Kagan, Y.Y. and Mulargia, F. (1997) Earthquakes Cannot Be Predicted. Science, 275, 1616-1617. https://doi.org/10.1126/science.275.5306.1616

[6] Bolt, B.A. (1978) Earthquakes: A Primer. W.H. Freeman and Company, San Francisco, 112-115.

[7] Bürgmann, R. and Dresen, G. (2008) Rheology of the Lower Crust and Upper Mantle: Evidence from Rock Mechanics, Geodesy, and Field Observations. Annual Re- 
view of Earth and Planetary Sciences, 36, 531-567.

https://igppweb.ucsd.edu/ fialko/rheo/Burgmann_AnnRev_2008.pdf https://doi.org/10.1146/annurev.earth.36.031207.124326

[8] Richter, C.F. (1958) Elementary Seismology. W.F. Freeman and Company, San Francisco, and Bailey Bros, Swinfen Ltd., London.

[9] Shrestha, B. (2009) Vertical Ground Motions and Its Effect on Engineering Structures: A State-of-the-Art Review. https://www.researchgate.net/publication/233922546

[10] Bozorgnia, Y. (2014) Vertical Ground Motion. http://www.cosmos-q.org/technicalsession/TS2014/5_Bozorgnia_2014.pdf

[11] Paonita, A., Caracausi, A., Martelli, M. and Rizzo, A.L. (2016) Temporal Variations of Helium Isotopes in Volcanic Gases Quantify Pre-Eruptive Refill and Pressurization in Magma Reservoirs: The Mount Etna Case. Geology, 44, 499-502. https://doi.org/10.1130/G37807.1

[12] Kanamori, H. and Brodsky, E. (2004) The Physics of Earthquakes. Reports on Progress in Physics, 67, 1429-1496. https://doi.org/10.1088/0034-4885/67/8/R03

[13] Ouzounov, D., Pulinets, S., Romanov, A., Romanov, A., Tsybulya, K., Davidenko, D., Kafatos, M. and Taylor, P. (2011) Atmosphere-Ionosphere Response to the M9 Tohoku Earthquake Revealed by Joined Satellite and Ground Observations. Preliminary Results.

[14] Donne, D.D., Harris, A.J.L., Ripepe, M. and Wright, R. (2010) Earthquake-Induced Thermal Anomalies at Active Volcanoes. Geology, 38, 771-774. https://doi.org/10.1130/G30984.1

[15] Darwin, C. (1838) On the Connexion of Certain Volcanic Phenomena in South America, and on the Formation of Mountain Chains and Volcanoes, as the Effect of the Same Power by Which Continents Are Elevated. Transactions of the Geological Society, 5, 1842-1846.

[16] Kopnichev, Y.F. and Sokolova, I.N. (2017) Ring-Shaped Seismicity Structures in Southern California: Possible Preparation for Large Earthquake in the Los Angeles Basin. Geofizicheskie Protsessyi Biosfera, 16, 42-54. https://link.springer.com/article/10.1134/S0001433817080072

[17] Cande, S.C. and Stegman, D.R. (2011) Indian and African Plate Motions Driven by the Push Force of the Reunion Plume Head. Nature, 475, 47-52. https://doi.org/10.1038/nature10174

[18] Mavrodiev, S.C. (2004) On the Reliability of the Geomagnetic Quake as a Short Time Earthquake's Precursor for the Sofia Region. Natural Hazards and Earth System Sciences, 4, 433-447.

[19] Mavrodiev, S.C. (2016) Imminent Earthquake Forecasting on the Basis of Japan Intermagnet Stations, NEIC, NOAA and Tide Code Data Analysis. Open Journal of Earthquake Research, 5, 62-78. https://doi.org/10.4236/ojer.2016.51005

[20] Mavrodiev, S.C., Pekevski, L. and Kikuashvili, G. (2013) Results of BlackSeaHazNet Project-FP7 IRSES Project: Extended Executive Summary, Conclusion Workshop, BlackSeaHazNet Series 3, Sofia.

[21] Mavrodiev, S., Pekevski, L., Kikuashvili, G., Botev, E., Getsov, P., Mardirossian, G., Sotirov, G. and Teodossiev, D. (2015) On the Imminent Regional Seismic Activity Forecasting Using INTERMAGNET and Sun-Moon Tide Code Data. Open Journal of Earthquake Research, 4, 102-113. https://doi.org/10.4236/ojer.2015.43010

[22] Fedotov, S.A. (2006) Magmatic Feeding Systems and Mechanism of Volcanic Erup- 
tions. Nauka, Moscow, 230-231. (In Russian)

[23] Jaggar, T.A. (1947) Origin and Development of Craters. Geol. Soc. Am. Memoir 21. https://doi.org/10.1130/MEM21-p1

[24] Tazieff, H. (1980) The Smell of Sulfur. Mysl, Moscow. (In Russian)

[25] Huang, H.H., Lin, F.C., Schmandt, B., Farrell, J., Smith, R.B. and Tsai, V.C. (2015) The Yellowstone Magmatic System from the Mantle Plume to the Upper Crust. Science, 348, 773-776. https://doi.org/10.1126/science.aaa5648

[26] Devine, J.D., Sugurdsson, H., Davis, A.N. and Self, S. (1984) Estimates of Sulfur and Chlorine Yield to the Atmosphere from Volcanic Eruptions and Potential Climatic Effects. Journal of Geophysical Research, 89, 6309-6325. https://doi.org/10.1029/JB089iB07p06309

[27] Fukuhara, M. (2016) Possible Generation of Heat from Nuclear Fusion in Earth's Inner Core. Scientific Reports, 6, Article No. 37740.

https://www.nature.com/articles/srep37740 https://doi.org/10.1038/srep37740

[28] Ratis, Y.L. (2009) Neutrino Catalysis of Nuclear Synthesis Reactions in Cold Hydrogen. Concepts of Physics, 6, 525-541. https://doi.org/10.2478/v10005-009-0011-4

[29] Rofman, V.M. (2012) To the Question of Genesis of Tritium in the Water of River Chagan (Semipalatinsk Anomaly, Kazachstan). (In Russian)

http://earth-chronicles.ru/news/2012-08-30-29679

[30] Shomer, I. (2010) Is Deuterium Fusion Catalyzed by Antineutrinos? http://adsabs.harvard.edu/abs/2010APS..APR.Q8008S

[31] Prados-Estévez, F., Subashiev, A. and Nee, H. (2017) Strong Screening by Lattice Confinement and Resultant Fusion Reaction Rates in fcc Metals. Nuclear Instruments and Methods in Physics Research Section B, 407, 6772. https://doi.org/10.1016/j.nimb.2017.05.047

[32] Terez, E. and Terez, I. (2015) Fusion Reactions as the Main Source of the Earth's Internal Energy. Herald of the Russian Academy of Sciences, 85, 163-169. https://doi.org/10.1134/S1019331615020070

[33] Storms, E. (2012) An Explanation of Low-Energy Nuclear Reactions (Cold Fusion). Journal of Condensed Matter Nuclear Science, 9, 86-107.

[34] Meijer de, R.J. and van Westrenen, W. (2008) Assessing the Feasibility and Consequences of Nuclear Georeactors in Earth Core-Mantle Boundary Region, South African. Journal of Science, 104, 111-118.

[35] Araki, T., Enomoto, S., Furuno, K., Gando, Y., Ichimura, K., et al. (2005) Experimental Investigation of Geologically Produced Antineutrinos with KamLAND. Nature, 436, 499-503. https://doi.org/10.1038/nature03980

[36] Gando, A. (2011) The KamLAND Collaboration. Partial Radiogenic Heat Model for Earth Revealed by Geoneutrino Measurements. Nature Geoscience, 4, 647-651. https://doi.org/10.1038/ngeo1205

[37] Rusov, V.D., Linnik, E.P., Vashenko, V.N., Mavrodiev, S.Cht., Beglaryan, M.E., Zelentsova, T.N., Tarasov, V.A., Litvinov, D.A., Smoylar, V.P. and Vachev, B.I. (2011) Solar Dynamo as Host Power Pacemaker of Earth Global Climate, EU FP7 IRSES 2011 Project, Complex Research of Earthquake's Forecasting Possibilities, Seismicity and Climate Change Correlations. Ohrid, Macedonia, BlackSeaHazNet Series 1, 2-5.

[38] Semenov, N.N. (1956) Some Problems Relating to Chain Reactions and to the Theory of Combustion. Nobel Lecture, December 11, 1956. 
[39] Dahy, S.A. and Hassib, G.H. (2009) Discriminating Nuclear Explosions from Earthquakes at Teleseismic Distances. European Journal of Applied Sciences, 1, 47-52.

https://pdfs.semanticscholar.org/aa07/2d387060e2dda194711d153af0708e4e52de.pd $\underline{\mathrm{f}}$

[40] Gieras, M., Klemens, R., Rarata, G. and Wolański, P. (2006) Determination of Explosion Parameters of Methane-Air Mixtures in the Chamber of $40 \mathrm{dm}^{3}$ at Normal and Elevated Temperature. Journal of Loss Prevention in the Process Industries, 19, 263-270. https://www.sciencedirect.com/science/article/pii/S0950423005000550 https://doi.org/10.1016/j.jlp.2005.05.004

[41] Zhang, Q., Li, W. and Liang, H.M. (2012) Effect of Spark Duration on Explosion Parameters of Methane-Air Mixtures in Closed Vessels. Safety Science, 50, 1715-1721. https://www.sciencedirect.com/science/article/pii/S0925753512000914 https://doi.org/10.1016/j.ssci.2012.04.004

[42] Maranda, A. and Szymański, R. (2013) Tests on Critical Diameter and Detonation Velocity of Mixtures of Ammonium Nitrate (V) and Selected Organic Substances. CHEMIK, 67, 13-18.

http://www.chemikinternational.com/year-2013/year-2013-issue-1/tests-on-criticaldiame-

ter-and-detonation-velocity-of-mixtures-of-ammonium-nitrate-v-and-selected-org anic-substances-maranda-a-szymanski-r/

[43] Antillon, E. and Strachan, A. (2015) Mesoscale Simulations of Shockwave Energy Dissipation via Chemical Reactions.

[44] Taylor, S.R. (1975) Lunar Science: A Post-Apollo View. Pergamon Press Inc., New York.

[45] Toulhoat, H., Beaumont, V., Zgonnik, V., Larin, N. and Larin, V.N. (2012) Chemical Differentiation of Planets: A Core Issue. https://arxiv.org/ftp/arxiv/papers/1208/1208.2909.pdf

[46] Recanati, A., Kurz, M.D., Warren, J.M. and Curtice, J. (2012) Helium Distribution in a Mantle Shear Zone from the Josephine Peridotite. Earth and Planetary Science Letters, 359-360, 162. https://doi.org/10.1016/j.epsl.2012.09.046

[47] Subashiev, A. and Nee, H. (2017) Hydrogen Trapping at Divacancies and Impurity-Vacancy Complexes in Nickel: First Principles Study. Journal of Nuclear Materials, 487, 135-142. https://doi.org/10.1016/j.jnucmat.2017.01.037

[48] Jaupart, C., Labrosse, S. and Mareschal, J.S. (2015) Temperatures, Heat and Energy in the Mantle of the Earth.

http://perso.ens-lyon.fr/stephane.labrosse/sites/default/files/PDF/Jaupart_etal_ToG 2015.pdf

[49] Gufeld, I.L. and Matveeva, M.I. (2011) Barrier Effect of Degassing and Destruction of the Earth's Crust. Doklady Earth Sciences, 438, 677-680. https://doi.org/10.1134/S1028334X11050199

[50] Vol, A. (2014) Thermo-Electrochemical Processes of the Earth's Degassing Creating Geomagnetic Field and Changing Its Value and Direction (Thermodynamic Approach). International Journal of Geosciences, 5, 1219-1230.

http://www.scirp.org/journal/ijg https://doi.org/10.4236/ijg.2014.510101

[51] Cowen, R. (2013) Two-Laser Boron Fusion Lights the Way to Radiation-Free Energy. Nature. https://doi.org/10.1038/nature.2013.13914

[52] Hora, H., Eliezer, S., Kirchhoff, G.J., Nissim, N., Wang, J.X., Lalousis, P., Xu, Y.X., 
Miley, G.H. and Martinez-Val, J.M. (2017) Road Map to Clean Energy Using Laser Beam Ignition of Boron-Hydrogen Fusion. Laser and Particle Beams, 35, 730-740. https://doi.org/10.1017/S0263034617000799

[53] Galembeck, F., Burgo, T.A.L., Balestrin, L.B.S., Gouveia, R.F., Silva, C.A. and Galembeck, A. (2014) Friction, Tribochemistry and Triboelectricity: Recent Progress and Perpectives. http://pubs.rsc.org/-/content/articlehtml/2014/ra/c4ra09604e

[54] Tilling, R.I., Topinka, L. and Swanson, D.A. (1993) Eruptions of Mount St. Helens: Past, Present, and Future. U.S. Department of the Interior/U.S. Geological Survey, U.S. Government Printing Office, Washington DC, 20402.

[55] Kiser, E., Palomeras, I., Levander, A., Zelt, C., Harder, S., Schmandt, B., et al. (2016) Magma Reservoirs from the Upper Crust to the Moho Inferred from High-Resolution Vp and Vs Models Beneath Mount St. Helens, Washington State, USA. Geology, 44, 411-414. https://doi.org/10.1130/G37591.1

[56] Dzurisin, D. (2018) Mount St. Helens Retrospective: Lessons Learned since 1980 and Remaining Challenges.

[57] Olson, S. (2017) Eruption, the Untold Story of Mount St. Helens. W.W. Norton \& Company, New York, London.

[58] Sano, Y., Kagoshima, N., Takahata, N., Nishio, Y., Roulleau, E., Pinti, D.I. and Fischer, P. (2015) Ten-Year Helium Anomaly Prior to the 2014 Mt. Ontake Eruption. Scientific Reports, 5, Article No. 13069. https://doi.org/10.1038/srep13069

[59] Sano, Y. and Fischer, P.T. (2013) The Analysis and Interpretation of Noble Gases in Modern Hydrothermal Systems. In: Burnard, P., Ed., The Noble Gases as Geochemical Tracers, Springer-Verlag, Berlin, 249-317. https://doi.org/10.1007/978-3-642-28836-4_10

[60] Ozima, M. and Podosek, F.A. (1983) Noble Gas Geochemistry. Cambridge Univ. Press, Cambridge.

[61] Jean-Baptiste, P., Bougault, H., Vangriesheim, A., Charlou, J.L., Radford-Knoery, J., Fouquet, Y., Needham, D. and German, C. (1998) Mantle ${ }^{3} \mathrm{He}$ in Hydrothermal Vents and Plume of the Lacky Strike Site (MAR $37^{\circ} 17^{\prime} \mathrm{N}$ ) and Associated Geothermal Heat Flux. Earth and Planetary Science Letters, 157, 69-77. https://doi.org/10.1016/S0012-821X(98)00022-3

[62] Wright, R., Flynn, L.P., Garbeil, H., Harris, A.J.L. and Pilger, E. (2004) MODVOLC: Near-Real-Time Thermal Monitoring of Global Volcanism. Journal of Volcanology and Geothermal Research, 135, 29-49. https://doi.org/10.1016/j.jvolgeores.2003.12.008

[63] Wright, R. and Flynn, L. (2004) Space-Based Estimate of the Volcanic Heat Flux Into the Atmosphere During 2001 and 2002. Geology, 32, 189-192. https://doi.org/10.1130/G20239.1 